\title{
Electric Signals on and under the Ground Surface Induced by Seismic Waves
}

\author{
Akihiro Takeuchi, ${ }^{1}$ Kan Okubo, ${ }^{2}$ and Nobunao Takeuchi ${ }^{3}$ \\ ${ }^{1}$ Earthquake Prediction Research Center, Institute of Oceanic Research and Development, Tokai University, 3-20-1 Orido, \\ Shimizu-ku, Shizuoka 424-8610, Japan \\ ${ }^{2}$ Division of Information and Communications Systems Engineering, Tokyo Metropolitan University, 6-6 Asahigaoka, \\ Hino 191-0065, Japan \\ ${ }^{3}$ Research Center for Prediction of Earthquakes and Volcanic Eruptions, Graduate School of Science, Tohoku University, \\ 6-6 Aza-aoba, Aramaki, Aoba-ku, Sendai 980-8578, Japan
}

Correspondence should be addressed to Akihiro Takeuchi, atakeuchi@sems-tokaiuniv.jp

Received 31 May 2011; Revised 2 November 2011; Accepted 18 November 2011

Academic Editor: Laurence Jouniaux

Copyright ( $\odot 2012$ Akihiro Takeuchi et al. This is an open access article distributed under the Creative Commons Attribution License, which permits unrestricted use, distribution, and reproduction in any medium, provided the original work is properly cited.

We constructed three observation sites in northeastern Japan (Honjo, Kyowa, and Sennan) with condenser-type large plate electrodes $\left(4 \times 4 \mathrm{~m}^{2}\right)$ as sensors supported $4 \mathrm{~m}$ above the ground and with pairs of reference electrodes buried vertically at $0.5 \mathrm{~m}$ and $2.5 \mathrm{~m}$ depth (with a ground velocity sensor at Sennan only). Electrical signals of an earthquake (M6.3) in northeastern Japan were detected simultaneously with seismic waves. Their waveforms were damped oscillations, with greatly differing signal amplitudes among sites. Good positive correlation was found between the amplitudes of signals detected by all electrodes. We propose a signal generation model: seismic acceleration vertically shook pore water in the topsoil, generating the vertical streaming potential between the upper unsaturated water zone and the lower saturated water zone. Maximum electric earth potential difference was observed when one electrode was in the saturated water zone, and the other was within the unsaturated water zone, but not when the electrodes were in the saturated water zone. The streaming potential formed a charge on the ground surface, generating a vertical atmospheric electric field. The large plate electrode detected electric signals related to electric potential differences between the electrode and the ground surface.

\section{Introduction}

Many researchers throughout the world have explored abnormal electromagnetic phenomena preceding earthquakes, such as electromagnetic emissions [1] and ionospheric disturbances [2]. However, most such reports describe methods that are retrospective. Scientific proof of the precursors is apparently still elusive. Earthquake prediction by detection of such precursors cannot be realized easily at this stage. To make steady progress in the scientific study of seismoelectromagnetic precursors, we believe that it is important to prove, first of all, the existence of phenomena that occur at the occurrence of earthquakes and at the arrival of seismic waves and to evaluate these phenomena quantitatively.
First, the piezoelectric effects of quartz and electrokinetic effects of pore water will be regarded as the matter that couples seismic waves and electromagnetic phenomena. However, Ogawa and Utada previously simulated an electric signal induced by seismic waves in a piezoelectric body lying at shallow depth and concluded that the signals would be weak unless the ground motion was unusually strong [3]. On the other hand, Pride proposed, theoretically, coupling of electromagnetics and acoustics of porous media saturated with electrolyte [4] although the purpose of that study was not earthquake prediction. Bordes and coworkers confirmed such coupled phenomena using an experimental apparatus built in an ultrashielded chamber in a deep underground laboratory [5]. Garambois and Dietrich detected electric signals induced by a dynamite shot in the field and analyzed 


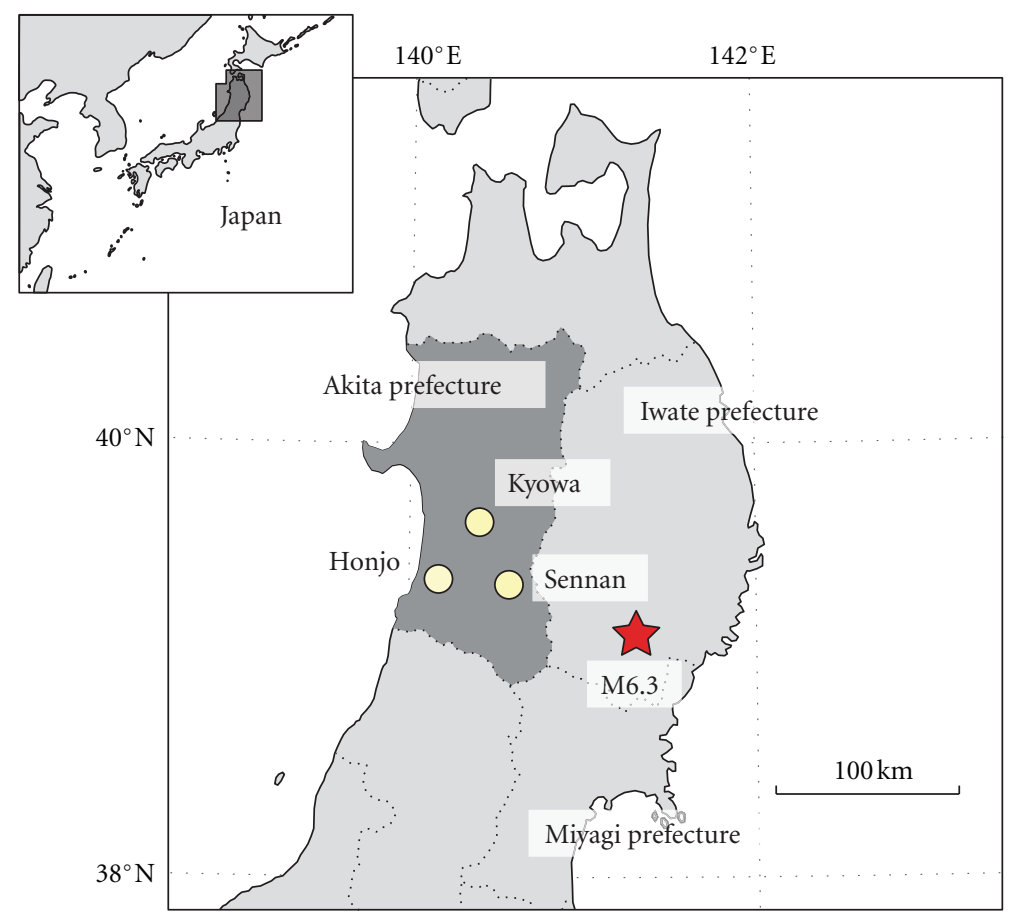

Figure 1: Location of three observation sites (Honjo, Kyowa, and Sennan) and the epicenter of an earthquake (M6.3) in northeastern Japan.

them in light of Pride's theory [6]. Consequently, it is expected that electromagnetic phenomena appear under the ground surface at the arrival of "natural" seismic waves, which are driven by the electrokinetic effect of pore water.

We have conducted observations of seismo-electromagnetic phenomena under the ground surface using electrodes buried in the ground. Additionally, we used condensertype plate electrodes supported above the ground surface. This paper describes the simultaneous detection of electrical signals by electrodes of both types at the arrival of natural seismic waves and discusses their generation models based on their streaming potential under several underground environmental circumstances, although results remain qualitative at this stage.

\section{Observation Sites and System}

Our first observation sites were in Miyagi Prefecture in northeastern Japan $[7,8]$. These sites had sensors of two types: (i) condenser-type electrodes supported above the ground surface by insulator pillars and (ii) reference electrodes buried horizontally and vertically under the ground surface. They detected electric signals at the arrival of seismic waves. The next site was located in Akita Prefecture in northeastern Japan [9]. This site had a similar set of sensors that also detected electric signals. We expected a relation between the signals and pore water in the ground and proposed a prototype model to explain the signals induced by the arrival of seismic waves. However, we had never detected a signal simultaneously at more than two sites until 2001. Therefore, we were unable to discuss a detailed model that was probably strongly related to the observation conditions.
In 2003, we prepared three new observation sites in Akita Prefecture in northeastern Japan. Figure 1 depicts the locations of the three observation sites.

(1) The Honjo observation site $\left(\mathrm{N} 39^{\circ} 23^{\prime}, \mathrm{E} 140^{\circ} 04^{\prime}\right)$ was located in a green belt on the Honjo Campus of Akita Prefectural University. To construct the campus, a hill surrounded by rice fields was leveled. The topsoil in this area was brown forest soil or gley soil with silt stones and conglomerates. No tall building existed near this site.

(2) The Kyowa observation site $\left(\mathrm{N} 39^{\circ} 40^{\prime}, \mathrm{E} 140^{\circ} 23^{\prime}\right)$ was located in a garden yard of a small recreation house of Akita Prefectural University on a flat land in the middle of mountains. The topsoil in this area was brown forest soil with acid tuff and sandstone. The area around this site was dotted with low-rise houses.

(3) The Sennan observation site $\left(\mathrm{N} 39^{\circ} 23^{\prime}, \mathrm{E} 140^{\circ} 30^{\prime}\right)$ was located on the sports ground of a former primary school surrounded by rice fields. The topsoil in this area was gley soil or sand-rich sediments. No tall building existed around this site.

Figure 2 presents a schematic of the observation system. They basically had sensors of two types: (i) a pair of reference electrodes (RE-5; M. C. Miller Co. Inc.) to detect the vertical component of the earth potential difference (EPD), and (ii) a large plate electrode to detect the signal related to the vertical component of the atmospheric electricity (AE). No tall building existed around the large plate electrodes. Therefore, we can reduce the atmospheric electricity disturbing because of such buildings. Only the Sennan observation site also 


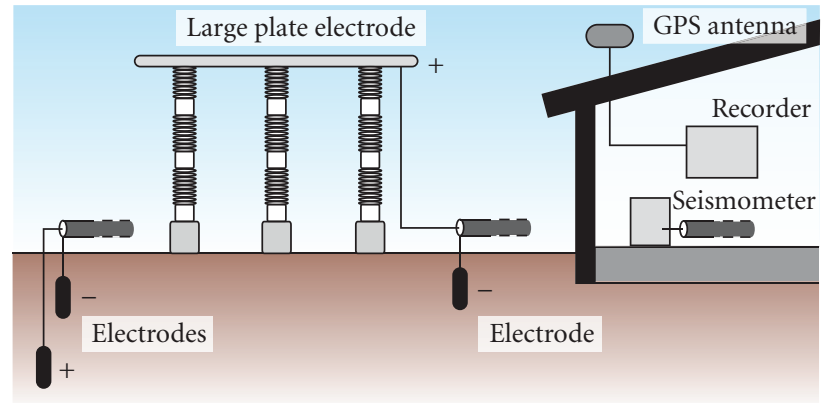

Figure 2: Schematic of the observation system. The pair of reference electrodes measured the vertical component of the earth potential difference (EPD). The positive electrode was buried $2.5 \mathrm{~m}$ deep; the negative one was buried $0.5 \mathrm{~m}$ deep. The aluminum large plate electrode measured signals related to the vertical component of the atmospheric electricity (AE). The plate area was $4 \times 4 \mathrm{~m}^{2}$. It was supported by five insulators at a height of about $4 \mathrm{~m}$. The velocity sensor (only at Sennan), which was fixed on the concrete base of a barn near the sensors, measured the up-down component of the ground surface velocity.

had a velocity sensor (L-22D; Mark Products LLC) to detect the up-down ground motion. All sensors were connected to a data recorder (DR-1021; DKK-TOA Corp.) with coaxial cables. A PC controlled the recorder and stored the data on its $\mathrm{HD}$ at $4 \mathrm{~Hz}$ sampling at the Honjo site and at $10 \mathrm{~Hz}$ sampling at the Kyowa and Sennan sites. The data clock was synchronized to within $1 \mathrm{~ms}$ of the time accuracy using a GPS unit.

Results confirmed that no disturbance appeared in EPD data by minute displacement of the electrodes buried in the ground or by movement of the coaxial cables. Based on our observation experiences $[7,8]$, we selected the electrode pairs buried vertically rather than horizontally, which can minimize the effects of artificial noise superimposed on the natural telluric currents flowing horizontally. The large plate electrodes were tested under various weather conditions such as heavy snow from August 2000. Thereafter, ordinary observations in the three sites started in May 2001. Although the system worked well during 2001-2006, it became too old to use in 2007: it was difficult to maintain and repair. Therefore, we dismantled the system in 2009.

\section{Observation Results}

Small earthquakes occurred in and around Akita Prefecture, sometimes causing weak electric signals at the Sennan observation site at the arrival of seismic waves [9]. When a major earthquake occurred in Iwate Prefecture (Figure 1), it caused electric signals at all three sites. We specifically examine this earthquake, which was the only major earthquake occurring around this area during 2001-2006. It occurred at 22:02 JST $(=\mathrm{UT}+9 \mathrm{hr})$ on December 2, 2001. Its magnitude was 6.3 on the Japan Meteorological Agency (JMA) scale. The epicenter was $\left(\mathrm{N} 39^{\circ} 23^{\prime}, \mathrm{E} 141^{\circ} 16^{\prime}\right)$, with focal depth of $130 \mathrm{~km}$. The focal depth of this earthquake was so great that the hypocentral distances of the three sites were almost identical. In general, local seismic intensity depends strongly on the site environments and the propagation paths of seismic waves. However, JMA seismometers around our three observation sites indicated the local seismic intensity of 3-4 on the JMA scale that is classified into 10 ranks. Therefore, we can assume that the local seismic intensities at the sites were similar.

Figure 3 portrays plots of raw data before and after the arrival of seismic waves at each site. The upper rows show raw EPD, the middle ones show raw $\mathrm{AE}$, and the lower one shows the raw ground velocity at the Sennan site. The time range is 22:00-22:05 JST. Dotted lines show the time of origin of the earthquake. Vibrating waveforms are confirmed, although some are small against background variations. These background variations were probably the result of local variations of atmospheric electricity, power line noise, and wind. To clarify the waveforms that are of interest for this study, we adopted the moving average method. In this study, the time period of $1 \mathrm{~s}$ was used for calculation of the moving average. The $1 \mathrm{~s}$ moving averages were subtracted from the original data, yielding the remnant waveforms as shown in Figure 4. The result clarifies that the damped oscillations are induced simultaneously in EPD and $\mathrm{AE}$ at the arrival of seismic waves, although some of them still include background noise, probably from power lines. Spectrum analyses show that both signals have a peak at about $1 \mathrm{~Hz}$. The outline waveforms of the induced EPD and AE signals are similar to that of the ground velocity at the Sennan site. Those at Honjo and Kyowa will be also similar to those of the ground velocity at each site.

Figure 5 shows the relation between the average amplitudes of the induced EPD and AE signals ( $\overline{\mathrm{EPD}}$ and $\overline{\mathrm{AE}}$, resp.). They are defined as shown below

$$
\begin{aligned}
& \text { average } \\
& =\sqrt{\frac{1}{30(\mathrm{~s})} \sum_{\text {peak time }(t=0(\mathrm{~s}))}^{t=30(\mathrm{~s})}(\text { induced signal }+ \text { background }(t))^{2}} \\
& -\sqrt{\frac{1}{30(\mathrm{~s})} \sum_{\text {no propagation }\left(t^{\prime}=0(\mathrm{~s})\right)}^{t^{\prime}=30(\mathrm{~s})}\left(\text { background }\left(t^{\prime}\right)\right)^{2}} .
\end{aligned}
$$




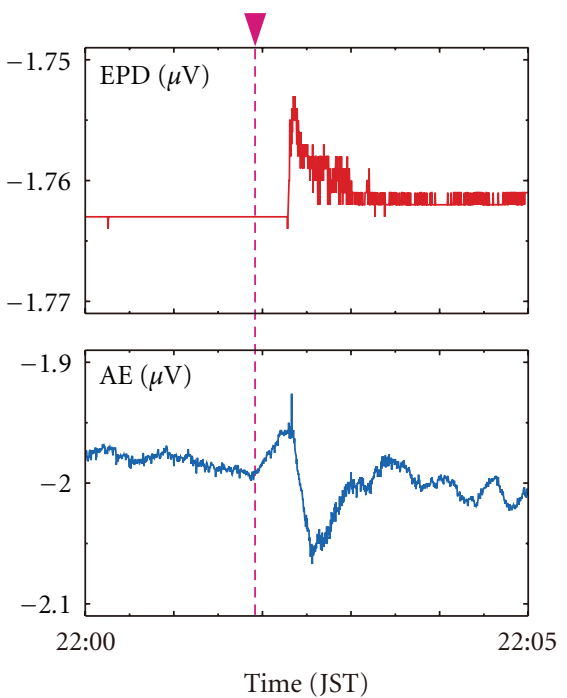

Time (JST)

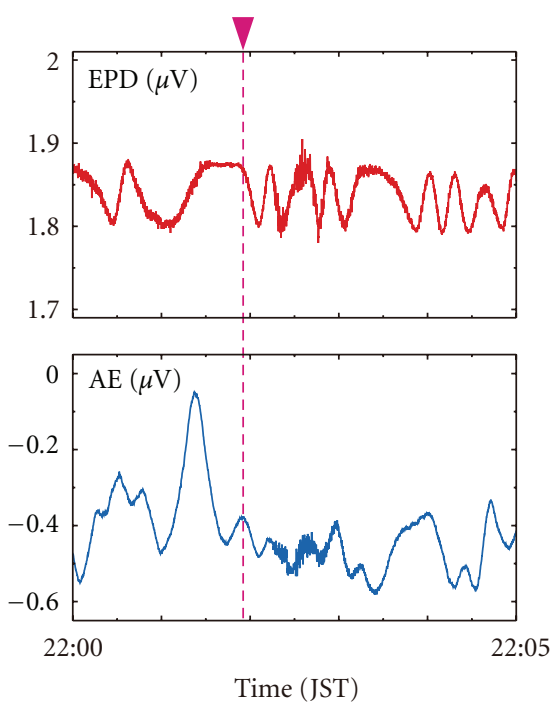

Time (JST)
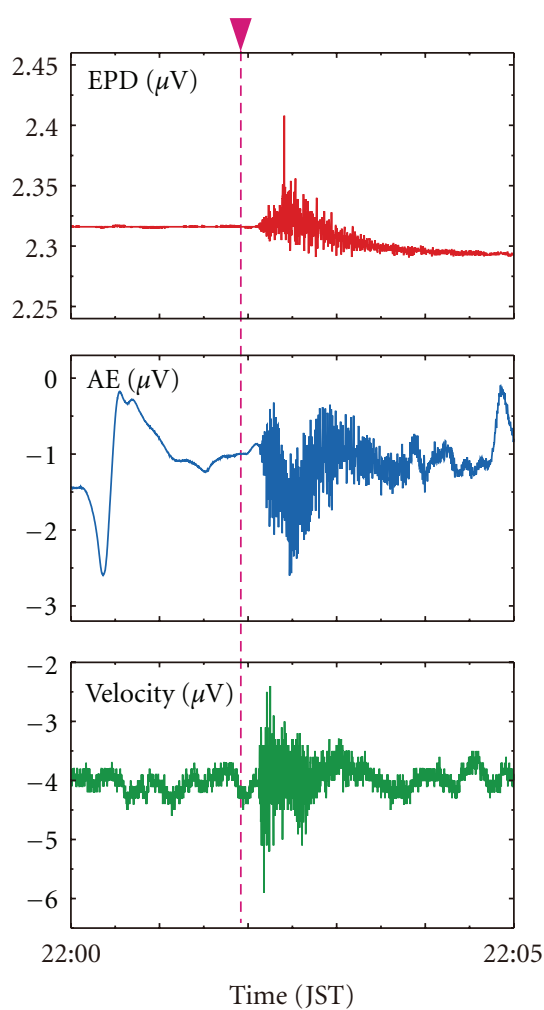

(c) Sennan

(a) Honjo

(b) Kyowa

FIGURE 3: Raw data recorded before and after the arrival of seismic waves from a M6.3 earthquake: (a) at Honjo, (b) at Kyowa, and (c) at Sennan. Upper row graphs show raw data of the earth potential difference (EPD). Middle ones show raw data of the signals related to the atmospheric electricity (AE). Lower one shows raw data of the ground velocity (only at Sennan). Broken lines show the origin time. The time is in JST $(=\mathrm{UT}+9 \mathrm{hr})$.

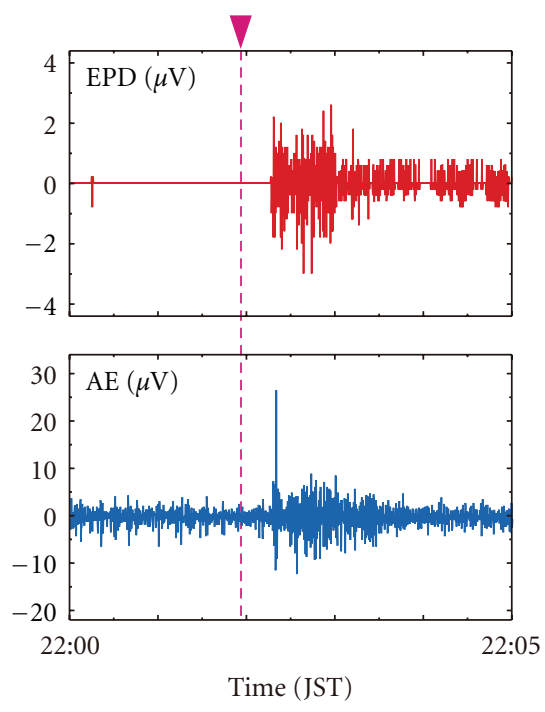

(a) Honjo

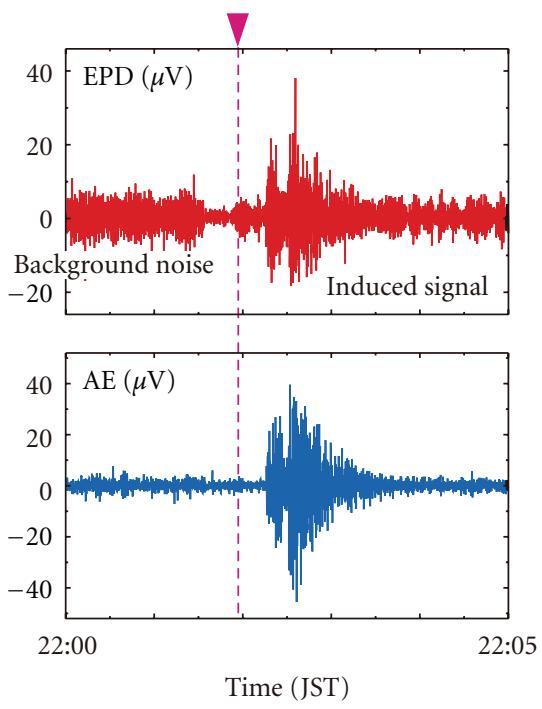

(b) Kyowa

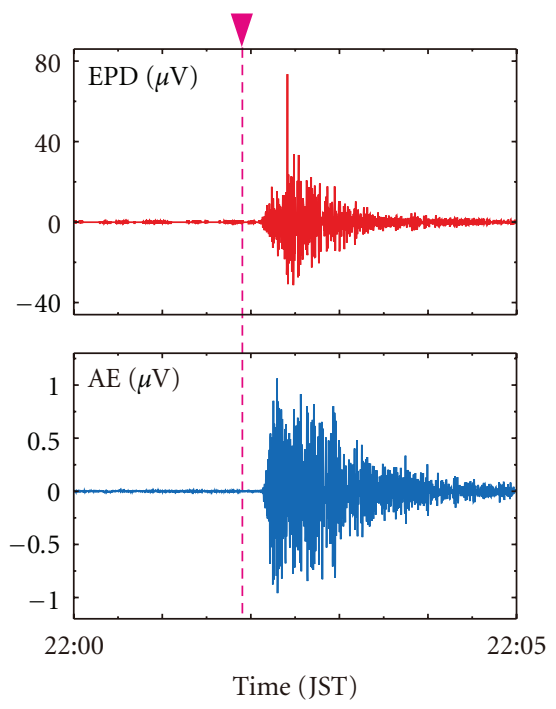

(c) Sennan

FIgURE 4: Waveforms extracted from raw data presented in Figure 3 using the 1 s moving average method: (a) at Honjo, (b) at Kyowa, and (c) at Sennan. Broken lines mean the origin time. The time is in JST $(=\mathrm{UT}+9 \mathrm{hr})$. 


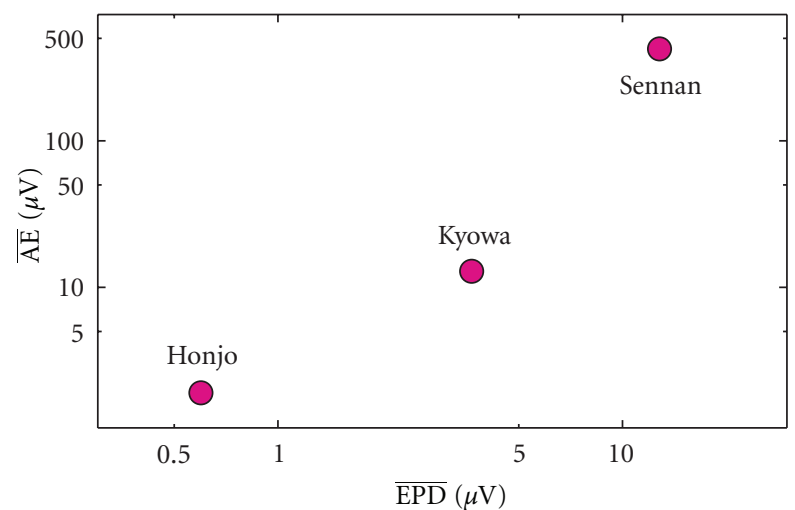

FIGURE 5: Positive correlation between the average of the induced earth potential difference $(\overline{\mathrm{EPD}})$ and the average of the induced atmospheric electricity $(\overline{\mathrm{AE}})$.

The summation in the first root is over a period of $30 \mathrm{~s}$ after the peak time of the induced EPD and AE signals; another in the second root is over a period of $30 \mathrm{~s}$ when no seismic wave propagated. Figure 5 depicts a positive relation between $\overline{\mathrm{EPD}}$ and $\overline{\mathrm{AE}}$. Although the local seismic intensity is probably similar among the three sites as described above, the $\overline{\mathrm{EPD}}$ and $\overline{\mathrm{AE}}$ at the Honjo site are smaller; those at the Sennan site are larger.

\section{Discussion}

4.1. Generation Mechanism of the Induced EPD Signals. We can list two effects as possible mechanisms generating the induced EPD signals. The first is a piezoelectric effect of quartz grains involved in the topsoil under the large plate electrodes. However, all observation sites were located on the topsoil, which was wet sometimes. Electric polarizations at each small quartz grain will be quite small. Moreover, polarization vectors will be random. Therefore, the vector summation is almost negligible. Furthermore, as described in the Introduction, an early simulation by Ogawa and Utada indicated that an electric signal induced by piezoelectric effect is expected to be weak [3]. In conclusion, the possibility of piezoelectricity is discounted. The second is an electrokinetic effect of pore water in the topsoil under the large plate electrodes. Our earlier observation data detected by similar sensors at a different site in Miyagi Prefecture and at Sennan site revealed a linear relation in log-log plots between the local seismic intensity and $\overline{\mathrm{EPD}}[7,9]$. Moreover, in those observations, the EPD waveform resembles that of the ground acceleration. Therefore, the force applied to pore water varies similarly to the EPD waveform. These results show that $\overline{\mathrm{EPD}}$ increases proportionally with the pressure difference in pore water. In this paper, we specifically examine the streaming potential caused by electrokinetic effect of pore water under seismic pressure.

From the viewpoint of geohydraulics, the water content generally increases with increased depth in the topsoil to be with pores. The upper is called the unsaturated water zone. The lower is called the saturated water zone $[10,11]$. Next, we consider only the vertical component. As portrayed in Figure 6(a), we assume the network of pores in the topsoil as a bundle of tubes connecting the air and the saturated water zone, as is often assumed also for the study of electric fields induced by the vertical fluid flow $[12,13]$. The upper part is a fine tube; the lower is a capillary tube. The lower part of the capillary tubes holds the pore water, called the capillary saturated water zone. The lower part is the saturated water zone, where the network of pore water is mutually and completely connected. It is noteworthy that such a bundle of tubes is not generated by seismic waves, but is instead a representation of the network of pores. Here, we assume that positive ions are predominant in water in the capillary tubes, although negative ions adhere to the tube inner walls. Maldistribution of positive and negative ions engenders the formation of electric potential difference between the center and wall of the tubes, called the zeta potential. Because this maldistribution depends on the soil type and the pore water $\mathrm{pH}[12,14]$, positive ions will adhere to the walls under different conditions.

Based on field observations and theoretical studies, it is well known that the seismic acceleration is coupled with the pore pressure $[15,16]$. This coupled dynamics must be valid in our geohydraulic system depicted in Figure 6(a). The wavelength of the seismic waves is much longer than the tube dimensions. Therefore, we can assume that the acceleration is uniform in our geohydraulic system. As indicated in Figure 6(b), when acceleration is inflicted upward in this system, the water in the capillary tubes flows upward along the tubes. In the real soil layer, soil grains function also as obstacles to the vertical water flow, so that a portion of the flow will bend in horizontal directions. Such horizontal flows deviated from each vertical flow will cancel each other. As a result, the vertical component of the flow remains. The tubes in our model represent the flow routes of the remnant vertical flow of pore water. Pride used a similar assumption to derive the coupled electromagnetics and acoustics of porous media from first principles [4].

The number of cations exceeds the number of anions in the diffuse layer of the electrical double layer in this system. Therefore, upward flow of the water engenders a positive electrification in the upper range of the tubes. However, the lower range of the tubes is negatively charged. Consequently, the vertical electric dipoles are formed and an electric potential difference (called streaming potential) appears between the upper level of the water flowing up and the saturated water zone. Because no more charge occurs above the upper level of the water, the electric potential in this range is almost constant or decreases because of a small amount of pore water in this range. When the positive and negative terminals of electrodes are buried, respectively, in the saturated water zone and the unsaturated water zone, they will detect a negative induced EPD signal. As Figure 6(c) shows, when acceleration is inflicted downward in this system, the opposite phenomena occur: the electrode will detect a positive induced EPD signal. Consequently, when seismic waves vertically oscillate this geohydraulic system, the electrodes detect an induced EPD signal that also oscillates. 


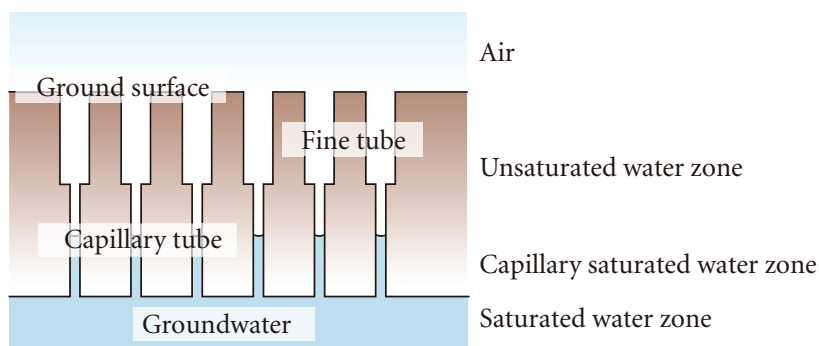

(a)

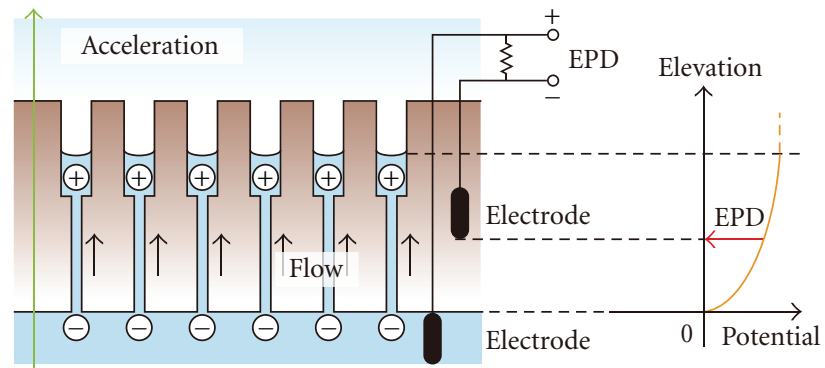

(b)

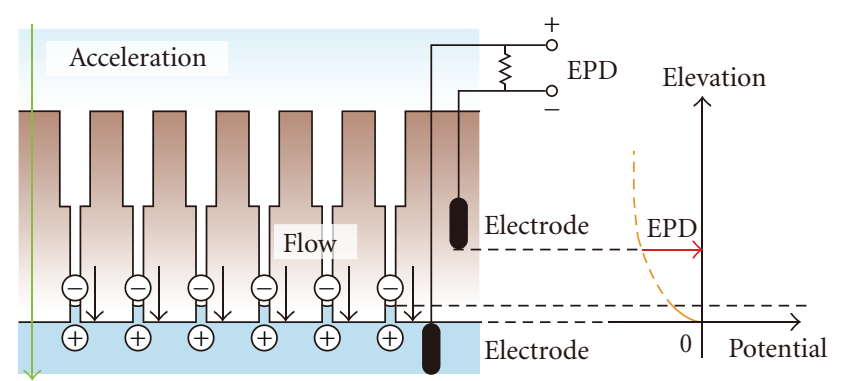

(c)

FIGURE 6: Generation model of the induced earth potential difference (EPD). (a) Model of the topsoil from the viewpoint of water saturation/unsaturation. (b) Generation of a negative EPD signal induced by streaming potential because of the upward flow of water along the tubes. (c) Generation of a positive EPD signal induced by streaming potential because of the downward flow of water along the tubes.

It is known that there are the underground electric fields produced by electric dipoles existing at the boundary between the capillary saturated water zone and the saturated water zone (the so-called water table) [17]. The dipoles are perpendicular to the boundary, and their polarity and amplitude depend, respectively, on the zeta potential and the conductivity of the saturated water zone. However, they do not reflect a transient effect, but a DC effect. Therefore, the transient movement of a seismic wave cannot move this boundary at this time scale. Consequently, the underground electric field produced by these dipoles will not contribute to the induced EPD signals in our observation system.

The amplitude of EPD signals will depend on the electrode positions in this geohydraulic system. Next we assume the six cases presented in Figure 7.

(a) When both electrodes are located mutually parallel in the unsaturated water zone (Figure $7(\mathrm{a})$ ), the induced EPD signals will be slight. Even if the streaming potential appears at the electrodes, the potential difference between them will be small. For example, in our previous similar observations at a different site [7], the vertical induced EPD signal was 10 times larger than the horizontal one, in which each electrode was separated by $2 \mathrm{~m}$.

(b) When one electrode is located in the unsaturated water zone and another is in the saturated water zone (Figure 7(b)), the induced EPD signals will be large. The electrode pair is located at both ends of electric polarization. Therefore, the electrodes detect the potential difference most effectively. Consequently, the amplitude becomes the maximum.

(c) When both electrodes are located in the saturated water zone (Figure 7(c)), the induced EPD signals will be slight. Because the pore water network is completely connected, this zone is sufficiently conductive. Most of the streaming potential will be canceled. For example, in our previous similar observation at a different site [7], two electrodes were buried at depths of $10 \mathrm{~m}$ and $12 \mathrm{~m}$, probably in the saturated water zone. They detected only very small induced EPD signals.

(d) When one electrode is located deep in the unsaturated water zone and another is deep in the saturated water zone (Figure $7(\mathrm{~d})$ ), the induced EPD signals will be large. This case resembles case (b). For example, in our previous similar observations at a different site [8], a pair of electrodes was buried at depths of $7 \mathrm{~m}$ and $10 \mathrm{~m}$. A borehole survey confirmed that the upper level of the saturated water zone was at $9 \mathrm{~m}$ depth. This site detected sufficiently large induced EPD signals against background variations.

(e) When both electrodes are located in the unsaturated water zone far from the deep saturated water zone (Figure 7(e)), the induced EPD signals will be very small. No pore water flows up in the upper range of the thick unsaturated water zone. Therefore, little potential difference appears between the electrodes.

(f) When one electrode is in the unsaturated water zone and another is near or above the saturated water zone 


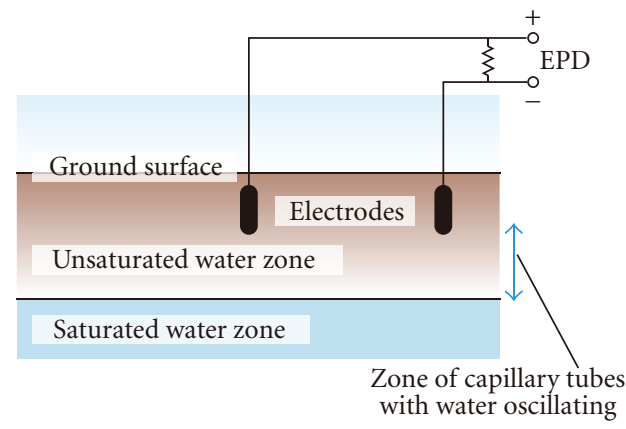

(a)

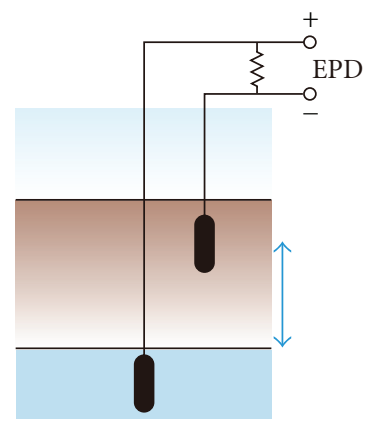

(b)

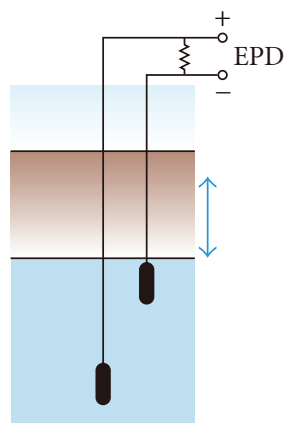

(c)

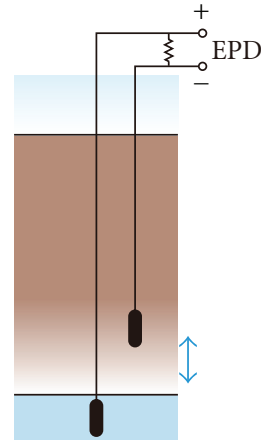

(d)

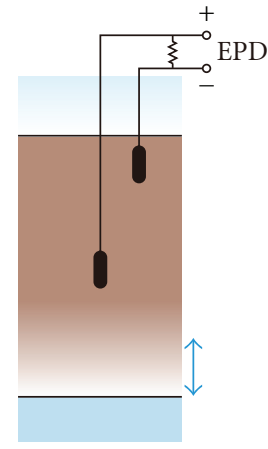

(e)

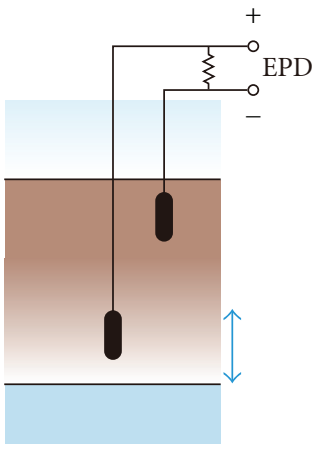

(f)

FIGURE 7: Various cases of locations with the electrode pair buried and with saturated/unsaturated water zone levels. (a) Both electrodes are mutually parallel in the unsaturated water zone. (b) One electrode is buried in the unsaturated water zone; another is buried in the saturated water zone. (c) Both electrodes are buried in the saturated water zone. (d) One electrode is deeply buried in the unsaturated water zone; another is buried deeply in the saturated water zone. (e) Both electrodes are buried in the unsaturated water zone far from the deep saturated water zone. (f) One electrode is buried in the unsaturated water zone; another is buried near but above the saturated water zone.

(Figure 7(f)), the induced EPD signals will be not so large. Until the lower electrode is buried in the water flowing up, no sufficient potential difference appears between the electrodes.

Because this model is based on streaming potential, $\overline{\mathrm{EPD}}$ depends on the zeta potential, that is, the soil type. However, as described above, the topsoil is fortunately similar among site areas: brown forest soil or gley soil. Therefore, we need not be so sensitively concerned about the soil type in this study. Nevertheless, according to reports of earlier studies, the apparent electrokinetic coefficient of a (un-)saturated medium reaches the maximum under the $70 \%$ saturation state, not under a perfectly saturated state [18]. This fact is concordant with our six models presented in Figure 7 because our model for the induced EPD signal is based on the electrokinetic effect, which is strongly related to the electrokinetic coefficient. For example, the saturated state of case (c) is $100 \%$. Therefore, the apparent electrokinetic coefficient is less than that in case (b). This engenders a decrease of $\overline{\mathrm{EPD}}$ in case (c). Here, we can expect that the significant difference of the $\overline{\mathrm{EPD}}$ among the three sites mainly results from differences in the position of the buried electrodes and saturated water zone.

(1) The Honjo observation site was located $6 \mathrm{~m}$ above the surrounding rice fields. The saturated water zone is expected to be a few meters deeper than the fields. Therefore, this site corresponds to case (e): the $\overline{E P D}$ was small.

(2) The Kyowa observation site was located on a flat land in the middle of mountains. Therefore, this site will correspond to case (f): the $\overline{\mathrm{EPD}}$ was not so large.

(3) The Sennan observation site was located on the same level as the surrounding rice fields. The saturated water zone will be a few meters deeper than the fields. Therefore, this site will correspond to case (b): the $\overline{\mathrm{EPD}}$ was large.

In case (b), the $\overline{\mathrm{EPD}}$ will be roughly equal to the streaming potential, as defined simply by

$$
\frac{\overline{\mathrm{EPD}}}{L}=\left|C \frac{P_{\text {bottom }}-P_{\text {top }}}{L}\right|,
$$

where $L$ (ca. 1-2 m) is the capillary water height, $C$ signifies the apparent electrokinetic coefficient, $P_{\text {bottom }}$ denotes the seismic pressure applied at the bottom of the capillary water, and $P_{\text {top }}$ stands for the pressure at the top. The value of $C$ is obtained as

$$
C=\frac{\varepsilon_{r} \varepsilon_{0} \zeta}{\eta \sigma}
$$


where $\varepsilon_{r}$ denotes the relative permittivity of capillary water, $\varepsilon_{0}\left(=8.8 \times 10^{-12} \mathrm{~F} / \mathrm{m}\right)$ represents the permittivity of vacuum, $\zeta$ is the zeta potential, $\eta$ stands for the viscosity of capillary water, and $\sigma$ signifies the electric conductivity of the capillary water. We have no concrete values for these parameters for our observation sites except $\sigma$ of approximately $0.01 \mathrm{~S} / \mathrm{m}$. Therefore, we simply apply standard values that are often used for order estimation: $\varepsilon_{r}$ of about $80,|\zeta|$ of about $10^{-2} \mathrm{~V}$, and $\eta$ of approximately $10^{-4} \mathrm{Pas}$ [19]. Using these values, we obtain $|C|$ of approximately $10^{-5} \mathrm{~V} / \mathrm{Pa}$. Moreover, Allègre and coworkers made a compilation that $|C|$ is of approximately $10^{-6} \mathrm{~V} / \mathrm{Pa}$ in the case of sands and sand stones at $\mathrm{pH}$ 7-8 [18]. Therefore, we adopt $|C|$ of approximately $10^{-6}-10^{-5} \mathrm{~V} / \mathrm{Pa}$ for this study. On the other hand, the $P_{\text {bottom }}$ is obtained from

$$
P_{\text {bottom }}=\frac{m a}{S}
$$

where $m\left(=m^{*} S L\right.$, with $\left.m^{*}=10^{3} \mathrm{~kg} / \mathrm{m}^{3}\right)$ represents the mass of the capillary water, $a$ is the seismic acceleration, and $S$ denotes the cross section of the capillary tube. The local seismic intensity 3 in the JMA scale has $a$ of about $10^{-1} \mathrm{~m} / \mathrm{s}^{2}$ at ca. $1 \mathrm{~Hz}$. Consequently, we obtain $P_{\text {bottom }}$ of ca. $10^{2} \mathrm{~Pa}$. By contrast, $P_{\text {top }}$ is approximately $0 \mathrm{~Pa}$ because nothing is on the top surface of the capillary water. Finally, we obtain $\overline{\mathrm{EPD}}$ of about $10^{-4}-10^{-3} \mathrm{~V}$, which is not so different from the value obtained from the observations at Sennan site.

4.2. Generation Mechanism of the Induced AE Signals. As shown in Figure 4, the induced AE signals appear in combination with the induced EPD signals. Moreover, as shown in Figure 5, a good positive correlation exists between $\overline{\mathrm{AE}}$ and $\overline{\mathrm{EPD}}$. Therefore, the generation mechanism of the induced AE signals must be coupled with that of EPD: both mechanisms are strongly related to streaming potential. Figure 8 presents a schematic diagram of a possible generation model of the induced AE signals in case (b) shown in Figure 7. As described in Figure 6, oscillation of the streaming potential appears in the unsaturated water zone. This is equivalent to oscillation of the electric dipoles vertical to the ground immediately under the ground surface. Their electric charges on the ground surface generate an atmospheric electric field vertical to the ground. Results show the appearance of oscillation of the electric potential difference between the large plate electrode and the ground surface. Electric charges move between the electrode and the ground through the recorder to cancel the potential oscillation. This movement is detected as oscillation of the induced AE signal.

Here, it is noteworthy that the recorded signal is not equal to the potential difference between the large plate electrode and the ground surface; the electric potential superimposed on the background variation is caused by a transient current passing through the internal resistance of the recorder. To obtain the original waveform of the induced $\mathrm{AE}$ signals, we need the integral of the recorded waveforms using different coefficients for each frequency. However, obtaining the coefficients is difficult. We have no concrete values to calculate the original $\mathrm{AE}$ signals at the present stage.

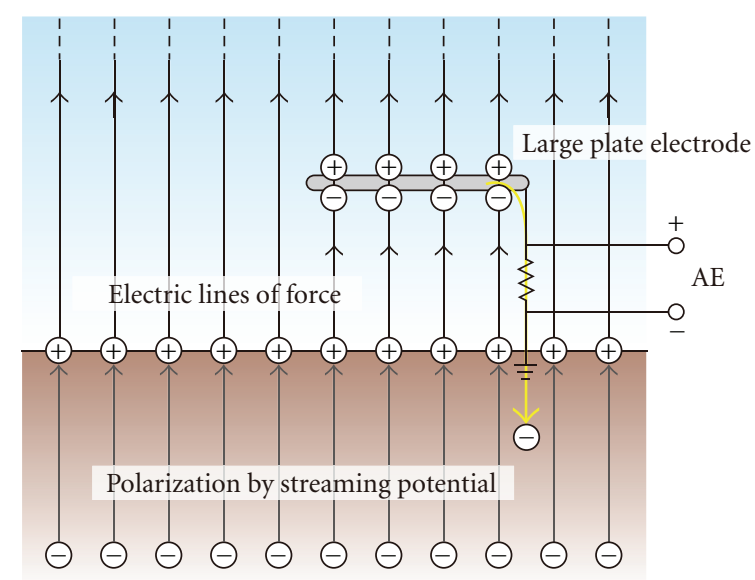

FIGURE 8: Generation model of induced atmospheric electricity (AE) coupled with generation of streaming potential in the topsoil.

Therefore, we must compare only the outwards of the signal amplitudes, as described in Section 3.

According to our model presented in Figure 8, a greater acceleration and a larger electrokinetic coefficient engender the higher charge density on the ground surface under certain good underground conditions such as those in case (b) of Figure 7. This engenders the larger atmospheric electricity. The Sennan observation site will correspond to this case. If this surface charge is sufficiently large, say ca. $5 \times 10^{-5} \mathrm{C} / \mathrm{m}^{2}$ [20], to cause dielectric breakdown of the air on the ground surface under a certain special condition, a dim light of corona discharge might appear in the atmosphere. This might be a possible mechanism of luminous phenomena accompanied with earthquakes, socalled earthquake lightning. If this field can be sufficiently large, say ca. $1 \mathrm{kV} / \mathrm{m}[21,22]$, in an extensive area under a certain special condition, then it might disturb plasma in the ionosphere. However, the charge density on the ground surface cannot be large in case (e) of Figure 7 because a portion of the electric field vertical to the ground will be absorbed in the thick upper unsaturated (but not dry) water zone. This engenders a decrease of the charge density on the ground surface. Consequently, only the small induced AE signal appears. The Honjo observation site corresponds to this case.

\section{Conclusions}

The Honjo, Kyowa, and Sennan observation sites in northeastern Japan detected the induced earth potential difference (EPD) signal and the induced atmospheric electricity (AE) signals at the arrival of seismic waves from a M6.3 earthquake near the sites. The signal waveforms were damped oscillations in combination with the seismic waves. Although the signal amplitudes were different at each site, good positive correlation was found between the averaged amplitudes of $\mathrm{EPD}(\overline{\mathrm{EPD}})$ and $\mathrm{AE}(\overline{\mathrm{AE}})$ signals. According to our coupled generation model of the electric signals based on streaming potential, the amplitude of the vertical atmospheric electric field is influenced strongly by the depth of the saturated 
water zone and the location of electric polarization because of electrokinetic effects. This model can explain the site dependence of $\overline{\mathrm{EPD}}$ and $\overline{\mathrm{AE}}$. According to this model, no guarantee exists that the amplitude of the vertical atmospheric electric field is strongest at the epicenter.

Although only one major earthquake simultaneously shook the observation sites during operations, this observation advanced our prototype generation model. The model proposed in this paper presents consideration of the actual underground environmental circumstances. Although it remains merely qualitative, we believe that it is a great step up to steady progress in the study of seismoelectromagnetic precursors. The next step is elucidation of the dynamic electric fields in the ground and accompanying magnetic fields, which are both induced by seismic waves. To do so, observation sites in the ground [23-26] that can detect three-dimensional dynamic electric/magnetic signals are also needed.

\section{Acknowledgments}

The authors thank Mr. Hiromi Ishikawa of Yurtec Corp., Akita, Japan, for his support in designing and constructing the large plate electrodes. They also thank two anonymous reviewers for their valuable comments on the paper.

\section{References}

[1] M. Hayakawa, Y. Kasahara, T. Nakamura et al., "A statistical study on the correlation between lower ionospheric perturbations as seen by subionospheric VLF/LF propagation and earthquakes," Journal of Geophysical Research A, vol. 115, no. 9, Article ID A09305, 2010.

[2] K. I. Oyama, Y. Kakinami, J. Y. Liu, M. Kamogawa, and T. Kodama, "Reduction of electron temperature in low-latitude ionosphere at $600 \mathrm{~km}$ before and after large earthquakes," Journal of Geophysical Research A, vol. 113, no. 11, Article ID A11317, 2008.

[3] T. Ogawa and H. Utada, "Electromagnetic signals related to incidence of a teleseismic body wave into a subsurface piezoelectric body," Earth, Planets and Space, vol. 52, no. 4, pp. 253-260, 2000.

[4] S. Pride, "Governing equations for the coupled electromagnetics and acoustics of porous media," Physical Review B, vol. 50, no. 21, pp. 15678-15696, 1994.

[5] C. Bordes, L. Jouniaux, S. Garambois, M. Dietrich, J. P. Pozzi, and S. Gaffet, "Evidence of the theoretically predicted seismomagnetic conversion," Geophysical Journal International, vol. 174, no. 2, pp. 489-504, 2008.

[6] S. Garambois and M. Dietrich, "Seismoelectric wave conversions in porous media: field measurements and transfer function analysis," Geophysics, vol. 66, no. 5, pp. 1417-1430, 2001.

[7] N. Takeuchi, N. Chubachi, and K. Narita, "Observations of earthquake waves by the vertical earth potential difference method," Physics of the Earth and Planetary Interiors, vol. 101, no. 1-2, pp. 157-161, 1997.

[8] N. Takeuchi, N. Chubachi, K. Narita, N. Honma, and T. Takahashi, "Characteristics of vertical earth potential difference signals," Transactions of IEE Japan, vol. 117-C, no. 5, pp. 554560, 1997 (Japanese).
[9] K. Okubo, M. Takayama, and N. Takeuchi, "Electrostatic field variation in the atmosphere induced by earth potential difference variation during seismic wave propagation," IEEE Transactions on Electromagnetic Compatibility, vol. 49, no. 1, pp. 163-169, 2007.

[10] G. N. Smith, Elements of Soil Mechanics for Civil and Mining Engineers, Collins, London, UK, 5th edition, 1982.

[11] D. F. McCarthy, Essentials of Soil Mechanics and Foundations: Basic Geotechnics, Prentice Hall, Upper Saddle River, NJ, USA, 7th edition, 2006.

[12] T. Ishido and J. Muzutani, "Experimental and theoretical basis of electrokinetic phenomena in rock-water systems and its applications to geophysics," Journal of Geophysical Research, vol. 86, no. B3, pp. 1763-1775, 1981.

[13] M. D. Jackson, "Multiphase electrokinetic coupling: insights into the impact of fluid and charge distribution at the pore scale from a bundle of capillary tubes model," Journal of Geophysical Research, vol. 115, Article ID B07206, 17 pages, 2010.

[14] X. Guichet, L. Jouniaux, and N. Catel, "Modification of streaming potential by precipitation of calcite in a sand-water system: laboratory measurements in the $\mathrm{pH}$ range from 4 to 12," Geophysical Journal International, vol. 166, no. 1, pp. 445460, 2006.

[15] R. Muir-Wood and G. C. P. King, "Hydrological signatures of earthquake strain," Journal of Geophysical Research, vol. 98, no. 12, pp. 22,035-22,068, 1993.

[16] R. Yan, Y. Chen, F. W. Gao, and F. Q. Huang, "Calculating Skempton constant of aquifer from volume strain and water level response to seismic waves at Changping seismic station," Acta Seismologica Sinica, vol. 21, no. 2, pp. 148-155, 2008.

[17] A. Revil, V. Naudet, J. Nouzaret, and M. Pessel, "Principles of electrography applied to self-potential electrokinetic sources and hydrogeological applications," Water Resources Research, vol. 39, no. 5, pp. SBH31-SBH315, 2003.

[18] V. Allègre, L. Jouniaux, F. Lehmann, and P. Sailhac, "Streaming potential dependence on water-content in Fontainebleau sand," Geophysical Journal International, vol. 182, no. 3, pp. 1248-1266, 2010.

[19] H. Mizutani, T. Ishido, T. Yokokura, and S. Ohnishi, "Electrokinetic phenomena associated with earthquakes," Geophysical Research Letters, vol. 3, no. 7, pp. 365-368, 1976.

[20] D. A. Lockner, M. J. S. Johnston, and J. D. Byerlee, "A mechanism to explain the generation of earthquake lights," Nature, vol. 302, no. 5903, pp. 28-33, 1983.

[21] S. A. Pulinets, K. A. Boyarchuk, V. V. Hegai, V. P. Kim, and A. M. Lomonosov, "Quasielectrostatic model of atmosphere-thermosphere-ionosphere coupling," Advances in Space Research, vol. 26, no. 8, pp. 1209-1218, 2000.

[22] Y. Rapoport, V. Grimalsky, M. Hayakawa et al., "Change of ionospheric plasma parameters under the influence of electric field which has lithospheric origin and due to radon emanation," Physics and Chemistry of the Earth, vol. 29, no. 4-9, pp. 579-587, 2004.

[23] K. Okubo, S. Sato, T. Ishii, and N. Takeuchi, "Observation of atmospheric electricity variation signals during underground seismic wave propagation," Transactions on Electrical and Electronic Engineering, vol. 1, no. 2, pp. 182-187, 2006.

[24] K. Okubo, N. Takeuchi, M. Utsugi, K. Yumoto, and Y. Sasai, "Direct magnetic signals from earthquake rupturing: IwateMiyagi earthquake of M 7.2, Japan," Earth and Planetary Science Letters, vol. 305, no. 1-2, pp. 65-72, 2011. 
[25] A. Takeuchi, K. Okubo, S. Watanabe, Y. Nakamura, and N. Takeuchi, "Electric and ionic environmental circumstances interacting at Hosokura underground mine in northeast Japan," IEEJ Transactions on Fundamentals and Materials, vol. 129, no. 12, pp. 870-874, 2009.

[26] A. Takeuchi, Y. Futada, K. Okubo, and N. Takeuchi, "Positive electrification on the floor of an underground mine gallery at the arrival of seismic waves and similar electrification on the surface of partially stressed rocks in laboratory," Terra Nova, vol. 22, no. 3, pp. 203-207, 2010. 

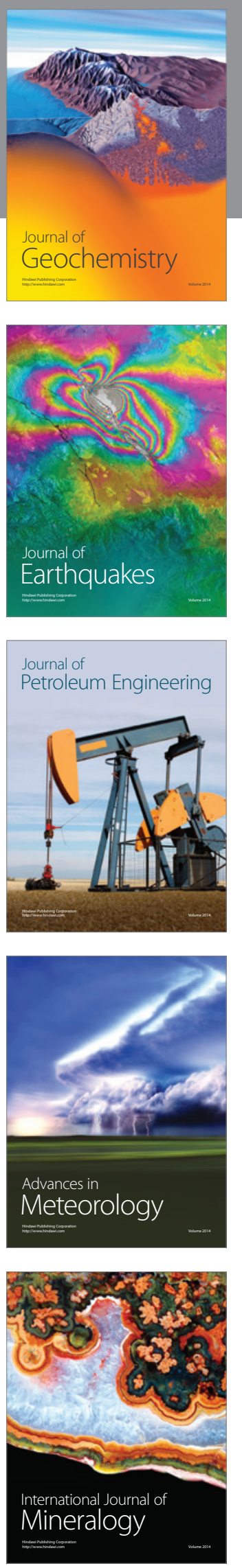
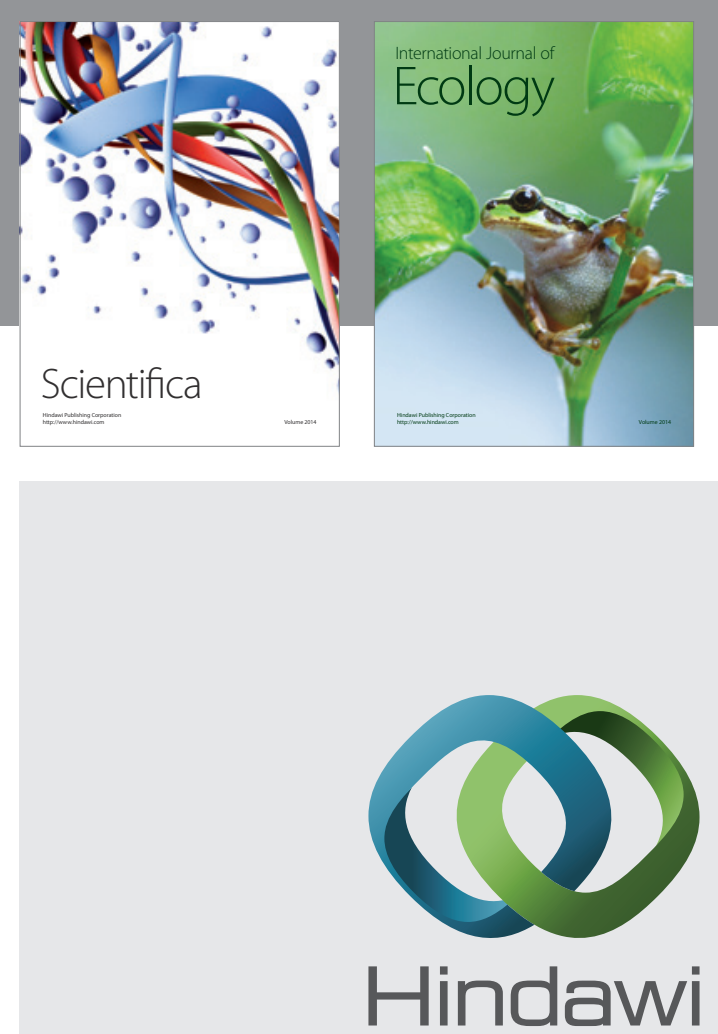

Submit your manuscripts at http://www.hindawi.com
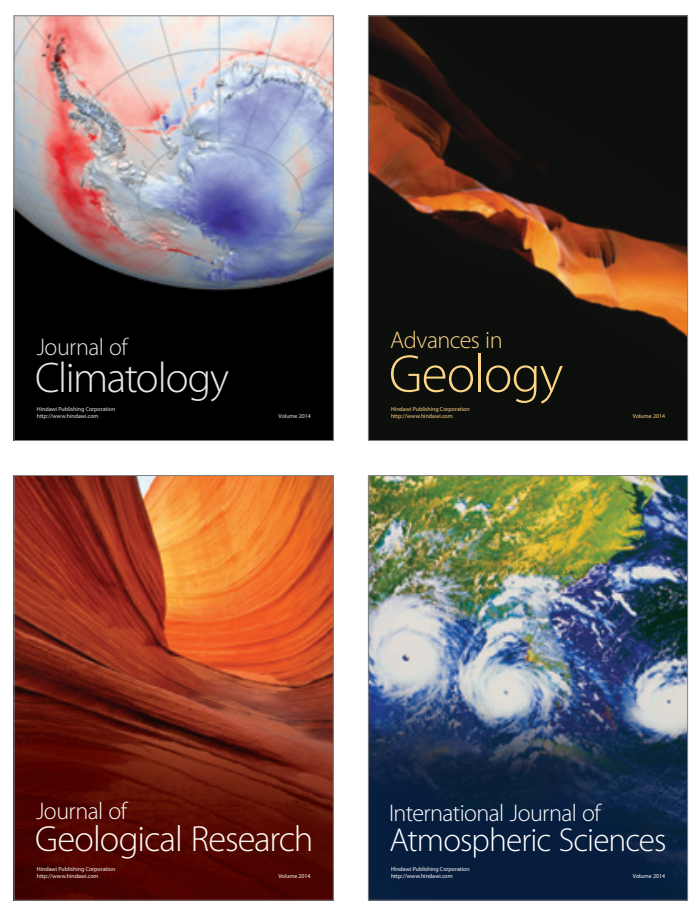
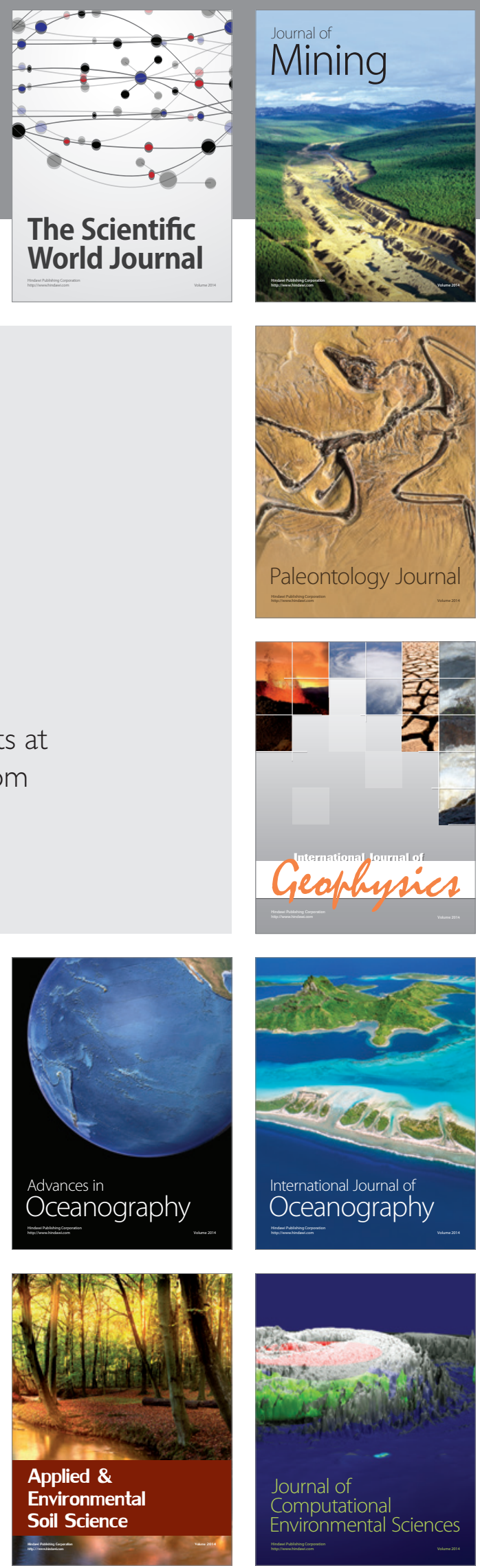